\title{
Differences of Respiratory Rate between Salbutamol and Aminophylline in Exacerbation Asthma
}

\author{
Amelia Lorensia $^{1 *}$, Zullies Ikawati ${ }^{2}$, Tri M. Andayani ${ }^{2}$, Daniel Maranatha ${ }^{3}$ \\ ${ }^{1}$ Department of Clinical Pharmacy-Community, Faculty of Pharmacy, University of Surabaya, Indonesia \\ ${ }^{2}$ Department of Pharmacology and Clinical Pharmacy, Faculty of Pharmacy, Universitas Gadjah Mada, Indonesia \\ ${ }^{3}$ Department of Pulmonology and Respiratory Medicine, Faculty of Medicine, University of Airlangga, Surabaya
}

Submitted 12 June 2018; Revised 13 May 2019; Accepted 21 August 2019; Published 03 February 2020

*Corresponding author:amelia.lorensia@gmail.com

\begin{abstract}
Exacerbation of asthma is a progressive step in progressive breathing, coughing, wheezing, breathing. In Indonesia salbutamol nebulation is used for the therapy of the first exacerbation attack. The effectiveness of asthma exacerbation therapy needs to be monitored and one of the monitoring parameters that is easily seen is the rate of breath.The aim of this study was to investigate the difference in respiratory rate values using salbutamol nebulisation and intravenous aminophylline in patients with asthma exacerbations in hospitals in Surabaya. The research was conducted by using quasi experimental method and data collection by purposive sampling. Analysis of the data to be used is a independent t-test. The results showed that the salbutamol group decreased respiratory rate by $50.00 \%$, there were also patients who experienced an increase of breath rate of $13.64 \%$. In the aminophylline group experienced a decrease in respiratory rate of $43.75 \%$ with an increase of breath rate of $18.75 \%$. From the results of the study, it is necessary to monitor the effectiveness and the need to monitor the unwanted reactions of both treatments so that the therapies produced in the treatment of asthma exacerbations are more effective.
\end{abstract}

Keywords: Aminophylline, exacerbation asthma, respiratory rate, salbutamol

\section{Perbedaan Nilai Laju Nafas antara Salbutamol dan Aminofilin pada Eksaserbasi Asma}

\begin{abstract}
Abstrak
Eksaserbasi asma merupakan tahap peningkatan sesak napas secara progresif, batuk, mengi, sesaknafas. Di Indonesia salbutamol nebulasi digunakan untuk terapi serangan eksaserbasi pertama. Efektifitas terapi eksaserbasi asma perlu monitoring dan salah satu parameter monitoring yang mudah dilihat adalah laju nafas. Tujuan penelitian ini untuk mengetahui perbedaan nilai laju nafas yang menggunakan salbutamol nebulasi dan aminofilin intravena pada pasien dengan eksaserbasi asma di rumah sakit di Surabaya. Penelitian dilakukan menggunakan metode kuasi eksperimental dan pengambilan data dengan cara purposive sampling. Analisa data yang akan digunakan adalah uji t-test bebas. Hasil penelitian menunjukkan kelompok salbutamol yang mengalami penurunan nilai laju nafas sebanyak $50,00 \%$, terdapat juga pasien yang mengalami kenaikkan nilai laju nafas sebanyak 13,64\%. Pada kelompok aminofilin yang mengalami penurunan nilai laju nafas sebanyak 43,75\% yang mengalami kenaikan nilai laju nafas sebanyak $18,75 \%$. Dari hasil penelitian menunjukkan, perlu adanya monitoring efektifitas dan perlu adanya monitoring reaksi yang tidak dikehendaki dari kedua pengobatan tersebut supaya terapi yang dihasilkan dalam penangan eksaserbasi asma lebih efektif.
\end{abstract}

Kata Kunci: Aminofilin, eksaserbasi asma, laju nafas, salbutamol 


\section{Pendahuluan}

Asma memiliki gejala mengi, sesak nafas, dada terasa tertekan benda berat, dan batuk. Gejala asma dapat menyebabkan eksaserbasi asma yang merupakan tahap peningkatan gejala yang perlu penanganan cepat karena dapat berisiko menyebabkan kematian. ${ }^{1}$

Efektifitas terapi eksaserbasi asma perlu pemantauan secara terus menerus, dan salah satu parameter yang paling mudah adalah laju nafas, yang akan mengalami peningkatan pada eksaserbasi asma. Laju nafas merupakan salah satu tanda vital dalam pemeriksaan fisik saat eksaserbasi asma. ${ }^{1}$ Peningkatan laju nafas merupakan proses kompensasi paruparu supaya mendapatkan oksigen dalam jumlah yang dibutuhkan.,3 Peningkatan laju nafas menjadi salah satu indikator kebutuhan perawatan darurat. ${ }^{4,5}$ Namun perubahan laju nafas juga dapat disebabkan pengobatan asma seperti terapi asma dengan golongan kortikosteroid, ${ }^{6}$ beta-2 agonis (salbutamol), ${ }^{7-9}$ atau metilsantin. ${ }^{10-12}$

Salbutamol nebulasi dikenal sebagai lini pertama pengobatan eksaserbasi asma. ${ }^{1,13}$ Selain salbutamol nebulasi, aminofilin/teofilin merupakan obat yang sering digunakan pada serangan asma, ${ }^{14-18}$ dan terdaftar dalam DOEN (2013) sebagai salah satu terapi eksaserbasi asma dengan pemberian intravena. ${ }^{13}$ Aminofilin merupakan pro-drug teofilin, memiliki efek bronkodilator dan anti inflamasi dalam mengatasi gejala asma. ${ }^{19}$ Aminofilin terbukti aman dan efektif dalam pengobatan eksaserbasi asma. ${ }^{14-18}$

Aminofilin merupakan obat dengan rentang terapi sempit yang berisiko menyebabkan efek samping. ${ }^{20,21}$ Oleh karena itu penggunaannya di luar negeri sudah jarang digunakan karena efek samping yang ditimbulkan dan efektifitas cenderung kecil dibandingkan salbutamol. ${ }^{1}$

Berbeda di Indonesia, aminofilin justru memberikan efektifitas baik dan kejadian efek samping yang jarang, ${ }^{14-18}$ bahkan cenderung tidak berbeda. ${ }^{18,22}$ Hal ini dapat disebabkan efek obat yang bersifat individual, dimana faktor genetik akan sangat berpengaruh dalam respon obat di dalam tubuh. ${ }^{2}$
Pada penelitian ini nilai laju nafas dibagi menjadi beberapa kategori: bradipnea $(<12 \mathrm{x} /$ menit $)$, takipnea $(>20 \mathrm{x} /$ menit $)$, dan normal (12-20 $\mathrm{x} / \mathrm{menit}){ }^{23}$ Namun selain karena tingkat keparahan eksaserbasi asma, obat yang digunakan untuk terapi asma juga dapat menyebabkan efek samping berupa peningkatan laju nafas, baik pada salbutamol nebulasi ${ }^{24,25}$ dan aminofilin intravena. ${ }^{26,27}$

Efek obat ini dapat menganggu pemantauan efektifitas terapi eksaserbasi asma pada parameter laju nafas. Sehingga diperlukan penelitian untuk mengetahui perbedaan terapi aminofilin intravena dibandingkan dengan salbutamol nebulasi dalam mempengaruhi nilai laju nafas pada eksaserbasi asma.

\section{Metode}

\subsection{Desain Penelitian}

Desain penelitian ini adalah kuasi eksperimental. Setiap rumah sakit hanya mendapatkan satu perlakuan untuk terapi eksaserbasi asma yang sama pada semua subjek, yaitu terapi asma dengan nebulasi salbutamol (terapi B) atau terapi aminofilin intravena (terapi A). Penelitian ini dilakukan pada Januari 2014 sampai Juni 2016.

\subsection{Populasi dan Sampel (Subjek) Penelitian}

Populasi adalah semua pasien yang mengalami eksaserbasi asma di rumah sakit di Surabaya. Sampel penelitian (subjek penelitian) adalah semua pasien dengan eksaserbasi asma di semua rumah sakit di Surabaya yang memenuhi kriteria inklusi dan eksklusi penelitian.

Kriteria inklusi: usia dewasa $(\geq 18$ tahun $)^{28}$ dan tingkat eksaserbasi asma ringan-sedang. ${ }^{1}$ Sedangkan kriteria eksklusi: menggunakan kontrasepsi oral; hamil/ menyusui; gangguan fungsi ginjal/hati kronis; perokok; dan memiliki gangguan pernafasan lain.

\subsection{Prosedur Kerja}

Subjek penelitian terbagi menjadi dua kelompok yang masing-masing subjek akan mendapatkan terapi eksaserbasi asma selama 
1 jam, ${ }^{1}$ yaitu:

Kelompok A. Pada kelompok ini, diberikan aminofilin intravena, loading dose $6 \mathrm{mg} / \mathrm{kg} / \mathrm{jam}$ selama 20 secara perlahan, kemudian dilanjutkan dosis pemeliharaan dengan infus ( $\mathrm{NaCl} 0,9 \%)$ sebesar $5 \mathrm{mcg} / \mathrm{kg} /$ jam. ${ }^{29-31}$

Kelompok B. Pada kelompok ini, diberikan salbutamol nebulasi dosis 2,5 $\mathrm{mg}$ atau $2 \mathrm{ml}$ dari $0,5 \%$ (+ $2 \mathrm{ml}$ saline $).{ }^{1}$

Penghitungan respiratory rate dilakukan sebelum pasien mendapatkan terapi $\left(\mathrm{t}_{0}\right)$ dan satu jam setelah mendapatkan terapi $\left(\mathrm{t}_{1}\right)$.

Analisa data yang akan digunakan adalah uji t-test bebas, untuk membandingkan laju nafas saat jam ke-0 $\left(\mathrm{t}_{0}\right)$ dan jam ke- $1\left(\mathrm{t}_{1}\right)$ antara kelompok A dan B. Penelitian ini telah mendapatkan izin etik dari rumah sakit terkait dengan nomor 01/EC/KERS/2014.

\section{Hasil}

Terdapat pasien eksaserbasi asma yang menolak atau tidak dapat terlibat di dalam penelitian dengan alasan yang dapat dilihat pada Tabel 1. Penelitian ini melibatkan 27 orang subjek penelitian pada kelompok A (aminofilin intravena) dan 30 orang pada kelompok B (salbutamol nebulasi), dengan deskriptif lebih lanjut dapat dilihat pada Tabel 2.

Baseline awal laju nafas antara kelompok A (rata-rata: 21,30) dan kelompok B (rata-rata: 24,37) sama-sama diatas rentang normal. Setelah mendapatkan terapi eksaserbasi asma selama 1 jam, kedua kelompok mengalami peningkatan nilai laju nafas, pada kelompok A rata-rata meningkat 0,59 poin dan kelompok B meningkat 2,37 poin (Tabel 3).

Tabel 3 menggambarkan perincian perubahan laju. Perubahan laju nafas yang paling banyak dialami subjek penelitian adalah peningkatan laju nafas baik pada kelompok A $(44,44 \%)$ dan kelompok B $(53,33 \%)$. Tabulasi silang kaitan antara karakteristik dan perubahan laju nafas dapat dilihat pada Tabel 5.

Tabel 1. Kriteria Eksklusi dan Drop Out

\begin{tabular}{|c|c|}
\hline Kriteria Eksklusi & Jumlah Pasien \\
\hline Hamil & 4 \\
\hline usia $\leq 18$ tahun & 5 \\
\hline Mempunyai penyakit hati kronis & 4 \\
\hline Mempunyai penyakit jantung koroner & 3 \\
\hline Mempunyai penyakit PPOK (Penyakit Paru Obstruktif Kronis) & 9 \\
\hline Mempunyai penyakit tuberkulosis & 3 \\
\hline Perokok & 2 \\
\hline Total & 30 \\
\hline Kriteria Drop Out & Jumlah Pasien \\
\hline Mendapat terapi asma lain & 2 \\
\hline Tidak dapat diinjeksi & 2 \\
\hline Total & 4 \\
\hline Alasan Pasien menolak & Jumlah Pasien \\
\hline Takut jarum suntik & 10 \\
\hline Buru-buru & 5 \\
\hline Tidak diijinkan keluarga & 7 \\
\hline Pasien tidak memberi alasan jelas & 2 \\
\hline Total & 24 \\
\hline
\end{tabular}


Tabel 2. Karakteristik

\begin{tabular}{|c|c|c|c|c|c|c|}
\hline \multirow{2}{*}{$\begin{array}{l}\text { Karakter } \\
\text { Baseline }\end{array}$} & \multirow[t]{2}{*}{ Keterangan } & \multicolumn{2}{|c|}{ Kelompok A (n=27) } & \multicolumn{2}{|c|}{ Kelompok B $(n=30)$} & \multirow{2}{*}{$\begin{array}{l}\text { Homogenitas } \\
\quad \text { Nilai } p\end{array}$} \\
\hline & & Jumlah & $\begin{array}{l}\text { Persentase } \\
\quad(\%)\end{array}$ & Jumlah & $\begin{array}{l}\text { Persentase } \\
\quad(\%)\end{array}$ & \\
\hline \multirow[t]{2}{*}{ Jenis Kelamin } & Perempuan & 14 & 50,85 & 19 & 63,33 & 0,176 \\
\hline & Laki-laki & 13 & 48,15 & 11 & 36,67 & \\
\hline \multirow[t]{7}{*}{ Usia (tahun) } & Remaja akhir(17-25) & 5 & 18,52 & 7 & 23,33 & 0,075 \\
\hline & Dewasa awal(26-35) & 5 & 18,52 & 5 & 16,67 & \\
\hline & Dewasa akhir(36-45) & 7 & 25,93 & 5 & 16,67 & \\
\hline & Lansia awal(46-55) & 8 & 29,63 & 6 & 20,00 & \\
\hline & Lansia akhir(56-65) & 2 & 7,41 & 6 & 20,00 & \\
\hline & $>65$ & 0 & 0,00 & 1 & 3,33 & \\
\hline & Rata-rata & 40,11 & & 40,83 & & \\
\hline \multirow[t]{5}{*}{$\begin{array}{l}\text { Penyakit } \\
\text { Penyerta }\end{array}$} & $\begin{array}{l}\text { dislipidemia, diabetes } \\
\text { tipe } 2\end{array}$ & 0 & 0,00 & 1 & 3,33 & 0,000 \\
\hline & $\begin{array}{l}\text { dislipidemia, } \\
\text { hiperurisemia }\end{array}$ & 0 & 0,00 & 1 & 3,33 & \\
\hline & $\begin{array}{l}\text { diabetes tipe } 2 \text {, } \\
\text { gastritis }\end{array}$ & 0 & 0,00 & 1 & 3,33 & \\
\hline & gastritis & 0 & 0,00 & 1 & 3,33 & \\
\hline & Tidak ada & 27 & 100,00 & 26 & 86,67 & \\
\hline \multirow[t]{5}{*}{ Pekerjaan } & Ibu rumah tangga & 10 & 37,04 & 10 & 33,33 & 0,854 \\
\hline & Wiraswasata & 9 & 33,33 & 10 & 33,33 & \\
\hline & Karyawan & 4 & 14,81 & 5 & 16,67 & \\
\hline & pelajar-mahasiswa & 4 & 14,81 & 4 & 13,33 & \\
\hline & tidak bekerja & 0 & 0,00 & 1 & 3,33 & \\
\hline
\end{tabular}

Keterangan:

Bila nilai $\mathrm{p}>0,05$ artinya data tidak ada perbedaan antara kelompok A dan kelompok B

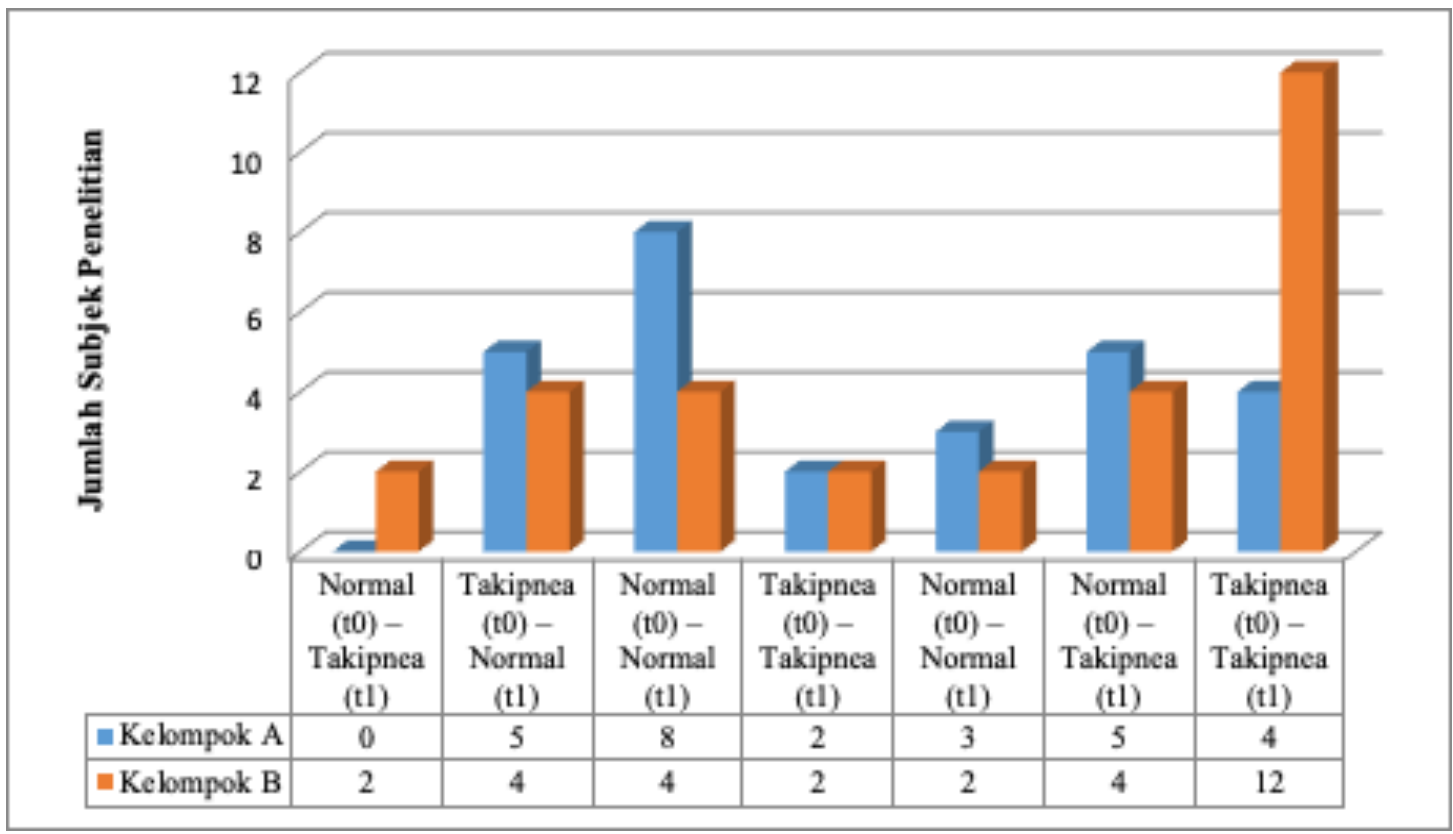

Gambar 1. Perubahan laju nafas 
Tabel 3. Nilai Laju Nafas

\begin{tabular}{|c|c|c|c|c|c|c|c|}
\hline \multirow{2}{*}{\multicolumn{2}{|c|}{$\begin{array}{c}\text { Klasifikasi Perubahan Laju } \\
\text { Nafas } \\
\text { (x/menit) }\end{array}$}} & \multicolumn{4}{|c|}{ Kelompok } & \multirow[t]{3}{*}{ Total } & \multirow{3}{*}{$\begin{array}{l}\text { Uji Beda } \\
\text { Nilai } p\end{array}$} \\
\hline & & \multicolumn{2}{|c|}{ Kelompok A $(\mathrm{n}=27)$} & \multicolumn{2}{|c|}{ Kelompok B $(\mathrm{n}=30)$} & & \\
\hline & & Jumlah & $\begin{array}{c}\text { Persentase } \\
(\%)\end{array}$ & Jumlah & $\begin{array}{c}\text { Persentase } \\
(\%)\end{array}$ & & \\
\hline \multirow[t]{4}{*}{$\mathrm{t}_{0}$} & Bradipnea & 0 & 0,00 & 0 & 0,00 & 0 & 0,235 \\
\hline & Normal & 16 & 59,26 & 12 & 40,00 & 28 & \\
\hline & Takipnea & 11 & 40,74 & 18 & 60,00 & 29 & \\
\hline & Rata-rata & 21,30 & & 24,37 & & & \\
\hline \multirow[t]{4}{*}{$t_{1}$} & Bradipnea & 0 & 0,00 & 0 & 0,00 & 0 & 0,141 \\
\hline & Normal & 16 & 59,26 & 12 & 40,00 & 28 & \\
\hline & Takipnea & 11 & 40,74 & 18 & 60,00 & 29 & \\
\hline & Rata-rata & 20,70 & & 22,00 & & & \\
\hline \multirow[t]{3}{*}{$\mathrm{t}_{0}-\mathrm{t}_{1}$} & Turun & 5 & 18,52 & 8 & 26,67 & 13 & 0,245 \\
\hline & Tetap & 10 & 37,04 & 6 & 20,00 & 16 & \\
\hline & Naik & 12 & 44,44 & 16 & 53,33 & 28 & \\
\hline
\end{tabular}

Keterangan:

Bila nilai $\mathrm{p}>0,05$ artinya data tidak ada perbedaan antara kelompok A dan kelompok B

$\mathrm{t}_{0} \quad=$ waktu awal sebelum diberikan terapi eksaserbasi asma (aminofilin intravena atau salbutamol nebulasi)

$\mathrm{t}_{1}=$ waktu awal sesudah diberikan terapi eksaserbasi asma (aminofilin intravena atau salbutamol nebulasi)

$\mathrm{t}_{0}-\mathrm{t}_{1}=$ perubahan/ selisih sesudah dengan sebelum diberikan terapi eksaserbasi asma (aminofilin intravena atau salbutamol nebulasi)

\section{Pembahasan}

Aminofilin merupakan penghambat sintesis dan sekresi mediator inflamasi yang mempunyai efektif melemaskan otot polos saluran napas, sehingga dapat mengurangi inflamasi kronik saluran napas. Gejala asma yang timbul seperti sesak napas dan rasa sesak di dada dapat terlihat dari kenaikkan nilai laju nafas pada pasien yang mengalami eksaserbasi asma. Obat golongan ShortActing Beta2 Agonis (SABA) termasuk salbutamol merupakan pilihan terapi yang

Tabel 4. Perubahan Laju Nafas

\begin{tabular}{|c|c|c|c|c|c|c|}
\hline \multicolumn{2}{|c|}{ Klasifikasi Perubahan Laju Nafas $\left(\mathrm{t}_{1}-\mathrm{t}_{0}\right)$} & \multicolumn{4}{|c|}{ Kelompok } & \multirow[t]{3}{*}{ Total } \\
\hline & & \multicolumn{2}{|c|}{ Kelompok A $(\mathrm{n}=27)$} & \multicolumn{2}{|c|}{ Kelompok B $(\mathrm{n}=30)$} & \\
\hline & & Jumlah & $\begin{array}{c}\text { Persentase } \\
(\%)\end{array}$ & Jumlah & $\begin{array}{c}\text { Persentase } \\
(\%)\end{array}$ & \\
\hline \multirow[t]{3}{*}{ Turun } & $\operatorname{Normal}\left(\mathrm{t}_{0}\right)-$ Takipnea $\left(\mathrm{t}_{1}\right)$ & 0 & 0,00 & 2 & 6,67 & 2 \\
\hline & Takipnea $\left(\mathrm{t}_{0}\right)-\operatorname{Normal}\left(\mathrm{t}_{1}\right)$ & 5 & 18,52 & 4 & 13,33 & 9 \\
\hline & TOTAL & 5 & 18,52 & 8 & 26,67 & 13 \\
\hline \multirow[t]{3}{*}{ Tetap } & $\operatorname{Normal}\left(\mathrm{t}_{0}\right)-\operatorname{Normal}\left(\mathrm{t}_{1}\right)$ & 8 & 29,63 & 4 & 13,33 & 12 \\
\hline & Takipnea $\left(\mathrm{t}_{0}\right)$-Takipnea $\left(\mathrm{t}_{1}\right)$ & 2 & 7,41 & 2 & 6,67 & 4 \\
\hline & TOTAL & 10 & 37,04 & 6 & 20,00 & 16 \\
\hline \multirow[t]{4}{*}{ Naik } & $\operatorname{Normal}\left(\mathrm{t}_{0}\right)-\operatorname{Normal}\left(\mathrm{t}_{1}\right)$ & 3 & 11,11 & 2 & 6,67 & 5 \\
\hline & $\operatorname{Normal}\left(\mathrm{t}_{0}\right)-$ Takipnea $\left(\mathrm{t}_{1}\right)$ & 5 & 18,52 & 4 & 13,33 & 9 \\
\hline & Takipnea $\left(\mathrm{t}_{0}\right)$-Takipnea $\left(\mathrm{t}_{1}\right)$ & 4 & 14,81 & 12 & 40,00 & 16 \\
\hline & TOTAL & 12 & 44,44 & 16 & 53,33 & 28 \\
\hline
\end{tabular}


Tabel 5. Tabulasi Silang Karakteristik dan Perubahan Laju Nafas

\begin{tabular}{|c|c|c|c|c|c|c|c|}
\hline \multirow{4}{*}{$\begin{array}{l}\text { Karakter } \\
\text { Baseline }\end{array}$} & \multirow[t]{4}{*}{ Keterangan } & \multicolumn{6}{|c|}{ Kelompok } \\
\hline & & \multicolumn{3}{|c|}{ Kelompok A (n=27) } & \multicolumn{3}{|c|}{ Kelompok B $(\mathrm{n}=30)$} \\
\hline & & \multicolumn{3}{|c|}{ Perubahan Nilai Laju Nafas $t_{0}-t_{1}$} & \multicolumn{3}{|c|}{ Perubahan Nilai Laju Nafas $t_{0}-t_{1}$} \\
\hline & & Turun & Tetap & Naik & Turun & Tetap & Naik \\
\hline \multirow{2}{*}{$\begin{array}{l}\text { Jenis } \\
\text { Kelamin }\end{array}$} & Perempuan & 6 & 4 & 1 & 8 & 2 & 3 \\
\hline & Laki-laki & 1 & 2 & 2 & 6 & 2 & 1 \\
\hline \multirow[t]{6}{*}{ Usia (tahun) } & Remaja akhir(17-25) & 2 & 1 & 0 & 3 & 1 & 2 \\
\hline & Dewasa awal(26-35) & 0 & 2 & 1 & 2 & 0 & 0 \\
\hline & Dewasa akhir(36-45) & 2 & 1 & 1 & 3 & 0 & 1 \\
\hline & Lansia awal(46-55) & 2 & 2 & 1 & 2 & 2 & 0 \\
\hline & Lansia akhir(56-65) & 1 & 0 & 0 & 4 & 0 & 1 \\
\hline & $>65$ & 0 & 0 & 0 & 1 & 0 & 0 \\
\hline
\end{tabular}

digunakan untuk mengurangi gejala-gejala asma tersebut. ${ }^{1,19}$

Faktor-faktor yang mempengaruhi perubahan nilai laju nafas adalah jenis kelamin dan usia. Pada umumnya laki-laki melakukan kegiatan lebih banyak daripada perempuan, sehingga tingginya energi yang dibutuhkan membutuhkan banyak oksigen supaya laju metabolisme tubuh meningkat sehingga laki-laki memiliki nilai laju nafas yang lebih tinggi daripada perempuan. Dan semakin bertambahnya usia seseorang nilai laju nafas mengalami penurunan hal ini berhubungan dengan kebutuhan energi yang semakin berkurang balita, anak-anak, dan remaja adalah masa pertumbuhan fisik yang butuh energi yang banyak. Sehingga laju metabolisme di dalam tubuh lebih cepat sehingga oksigen yang dibutuhkan lebih banyak. $^{32}$ Adapun faktor lain yang dapat mempengaruhi perubahan laju nafas seperti stress dan keadaan cemas. ${ }^{33,34}$

Hasil penelitian ini tidak terdapat perbedaan signifikan nilai laju nafas yang antara kedua kelompok. Pada kelompok A, yang mengalami penurunan nilai laju nafas (membaik) sebanyak 43,75\% sedangkan pasien dengan nilai tetap sebanyak 33,33\%. Sebaliknya pada kelompok B yang mengalami peningkatan nilai laju nafas sebanyak $53,33 \%$ dan 2 orang diantaranya mengalami peningkatan nilai hingga $>20 \mathrm{x} /$ menit. Hal ini diduga pasien mengalami efek samping salbutamol.
Laju nafas merupakan salah satu tanda vital dalam pemeriksaan fisik saat eksaserbsi asma. ${ }^{1}$ Terdapat penelitian terdahulu yang melibatkan laju nafas sebagai parameter penelitian, Hardasmalani et al. $(2005)^{35}$ yang membandingkan levalbuterol dan albuterol nebulasi untuk pengobatan eksaserbasi asma pada pasien anak. Peningkatan laju nafas merupakan proses kompensasi paru-paru supaya tetap mendapatkan oksigen dalam jumlah yang dibutuhkan. ${ }^{36}$

\section{Simpulan}

Tidak ada perbedaan nilai laju nafas pada penggunaan terapi aminofilin intravena dan salbutamol nebulasi pada eksaserbasi asma.

\section{Daftar Pustaka}

1. The Global Initiative for Asthma. Update of the GINA report:Global strategy for asthma management and prevention,2017.

2. Roden DM, Wilke RA, Kroemer HK, Stein CM. Pharmacogenomics:The Genetics of Variable Drug Responses. Circulation.2011;123(15):1661-1670.

3. Smith I, Mackay J, Fahrid N, Krucheck D. Respiratory Rate Measurement:a Comparison of Methods. British Journal of Helahcare Assistants.2011;5(1):18-23.

4. Adams JY, Sutter ME, Albertson TE. The Patient with Athma in the Emergency Departement. Clinic Rev Allerg Immunol.2012;43(2-1):14-29. 
5. Soubra SH, Kalapalatha K, Guntupalli. Acute Respiratory Failure in Asthma. 2009;9(4):225-234.

6. Stroeder J, Evans C, Mansell H. Corticosteroid-induced bradycardia. Can Pharm J (Ott).2015;148(5):235-240.

7. Khorfan FM, Smith P, Watt S, Barber KR. Effects of nebulized bronchodilator therapy on heart rate and arrhythmias in critically ill adult patients.Chest. 2011;140(6):1466-1472.

8. Kenyon CC, Fieldston ES, Luan X, Keren R, Zorc JJ. Safety and Effectiveness of Continuous Aerosolized Albuterol in the Non-Intensive Care Setting. Pediatrics.2014;134(4):e976-e982.

9. Prakash S, Sharma S, Miglani S, Gogia AR. Management of Intraoperative Penile Erection with Salbutamol Aerosol. Journal of Anaesthesiolog Clinical Pharmacology.2012;28(3):402-403.

10. Henderson-Smart DJ, De Paoli AG. Prophylactic methylxanthine for prevention of apnoea in preterm infants. Cochrane Database Syst Rev.2010;(12):CD000432.

11. Schoen K, Yu T, Stockmann C, Spigarelli MG, Sherwin CMT. Use of Methylxanthine Therapies for the Treatment and Prevention of Apnea of Prematurity. Paediatr Drugs.2014; 16(2):169-177.

12. Bioh G, Gallagher MM, Prasad U. Survival of a Highly Toxic Dose of Caffeine. BMJ Case Rep.2013; bcr2012007454.

13. Kementerian Kesehatan RI. Keputusan Menteri Kesehatan Republik Indonesia Nomor 312/MENKES/SK/IX/2013, tentang Daftar Obat Essensial 2013. Jakarta: Kementerian Kesehatan RI; 2013.

14. Lorensia A, Wahjuningsih E, Canggih B, Lisiska N. Pharmacist's Strategies in Treating Asthma Bronchiale Outpatient. Jurnal of Tropical Pharmacy and Chemistry.2011;1(3):177-191.

15. Lorensia A, Amalia RA. Studi Farmakovigilans Pengobatan Asma pada Pasien Rawat Inap di suatu Rumah Sakit di Bojonegoro. Jurnal Ilmiah Manuntung.
2015;1(1):8-18.

16. Lorensia A, Wahjuningsih E, Supriadi, 2012. Keamanan Penggunaan Aminofilin pada Asma di Rumah Sakit Delta Surya Sidoarjo. Indonesia journal of Clinical Pharmacy.2012;1(4):154-161.

17. Lorensia A, Wijaya RI. Hubungan Jumlah Obat yang Digunakan Terhadap Risiko Terjadinya Drug-Related Problems pada Pasien Asma di Suatu Rumah Sakit di Surabaya. Jurnal of Tropical Pharmacy and Chemistry. 2016;3(3):232-238.

18. Lorensia A, Ikawati Z, Andayani TM, Maranatha D, Wahjudi M. Comparison of Electrolyte Disturbance of Using Intravenous Aminophylline Versus Nebulization Salbutamol for Exacerbation Asthma in Surabaya, Indonesia. International Journal of Pharmaceutical and Clinical Research.2016;8(4):221-228.

19. Majumdar S, Mueller-Spaeth, Sloan KB. Prodrugs of theophylline incorporating ethyleneoxy groups in the promoiety: synthesis, characterization, and transdermal delivery.2012;13(3):853-62.

20. Hocaoğlu N, Yildıztepe E, Bayram B, Aydın B, Tunçok Y, Kalkan S. Demographic and Clinical Characteristics of Theophylline Exposures between 1993 and 2011. Balkan Med J.2014;31(4):322327.

21. Blix HS, Viktil KK, Moger TA, Reikvam A. Drugs with narrow therapeutic index as indicators in the risk management of hospitalised patients.2010;8(1):50-55.

22. Lorensia A, Ikawati Z, Andayani TM, Maranatha D, Wahjudi M. Analisis Kejadian Leukositosis Pasca Terapi Aminofilin Intravena Dibandingkan dengan Salbutamol Nebulasi pada Pasien Eksaserbasi Asma. Indonesia journal of Clinical Pharmacy. 2016;5(3):149-159.

23. Philip KE, Pack E, Cambiano V, Rollmann H, Weil S, O'Beirne J. The Accuracy of Respiratory Rate Assessment by Doctors in a London Teaching Hospital: a Crosssectional study. J Clin Monit Comput. 2015;29(4):455-460.

24. Cekici L, Valipour A, Kohansal R, Burghuber OC. Short-term effects 
of inhaled salbutamol on autonomic cardiovascular control in healthy subjects: a placebo-controlled study. $\mathrm{Br} \mathrm{J}$ Clin Pharmacol.2009;67(4):394-402.

25. Billington CK, Penn RB, Hall IP. B2Agonists. Handb Exp Pharmacol. 2017;233:23-40.

26. Mahemuti G, Zhang H, Li J, Tieliwaerdi $\mathrm{N}$, Ren L. Efficacy and side effects of intravenous theophylline in acute asthma: a systematic review and meta-analysis. Drug Des Devel Ther. 2018;12:99-120.

27. Nair P, Milan SJ, Rowe BH. Addition of intravenous aminophylline to inhaled beta(2)-agonists in adults with acute asthma. Cochrane Database Syst Rev. 2012;12:CD002742.

28. National Center for Chronic Disease Prevention and Health Promotion. Data source with asthma content: Behavioral risk factor surveillance system (BRFSS); 2011.

29. National Asthma Council Australia. Asthma Management Handbook [diunduh 28 November 2017]. Tersedia dari: https: //www.nationalasthma.org.au/health-prof essionals/australian-asthma-hand book
30. Fong N. Aminophylline/theophylline: Loading and maintenance dose. NHS Trust: East Lancashire Hospitals;2011.

31. Scottish Intercollegiate Guidelines Network. British guideline on the management of asthma, British Thoracic Society;2011.

32. Chester JG, Rudolph JL. Vital Signs in Older Patients: Age-Related Changes. J Am Med Dir Assoc.2011;12(5):337-343.

33. Grassmann M, Vlemincx E, Leupoldt AV, Mittelstadt JM, Bergh OV. Respiratory Changes in Response to Cognitive Load: A Systematic Review. Neural Plasticity.2016;8146809:1-16.

34. Vlemincx E, Diest V, Bergh VD. A sigh following sustained attention and mental stress: effects on respiratory variability. Physiol Behav.2012;107(1):1-6.

35. Hamdasmalani MD, DeBari V, Bithoney WG, Gold N. Levalbuterol versus racemic albuterol in the treatment of acute exacerbation of asthma in children. Pediatr Emerg Care.2005;21(7):415-9.

36. Troosters T, Dupont L, Bott J, Hansen K. Your Lungs anda Exercise. Breathe (Sheff).2016;12(1):97-100. 